\title{
Add Onion to Your Dishes to Clean Your Arteries
}

\author{
Dongfeng Wu* \\ Department of Bioinformatics and Biostatistics, University of Louisville, USA
}

*Corresponding author: Dongfeng Wu, Department of Bioinformatics and Biostatistics, School of Public Health and Information Sciences, University of Louisville, USA

To Cite This Article: Dongfeng Wu. Add Onion to Your Dishes to Clean Your Arteries. Am J Biomed Sci \& Res. 2019 - 4(1). AJBSR.MS.ID.000744. DOI: $10.34297 / A J B S R .2019 .04 .000744$

Received: June 12, 2018 | Published: July 12, 2019

\section{Opinion}

One of my close family members had some heart valve problems recently. He went through many heart-related tests, such as, electrocardiogram (EKG) [1], Echocardiogram test [2], transesophageal echo test (TEE) [2], and cardiac catheterization (CATH) [2], etc. The last one, CATH, is to check the coronary arteries blockage. Among all the bad news, one good result is that his blood vessels are very clean, without any build-up of fatty deposits, and even the doctor was a little bit surprised; since so many people are suffering from clogged arteries at this stage of life.

For the next few days, I was ponding the test result and trying to figure out what we eat regularly that may contribute to the clean arteries. I searched internet for heart healthy food [3]; many were listed, such as, leafy green vegetables, whole grains, berries, avocados, fish, nuts, beans, chocolate, tomatoes, garlic, olive oil, and green teas, etc. Of course, we eat many of them on the list. However, I think one most important item is missing, and that is onion! Let me tell you why I think onion is one of the most important ingredients in cleaning our blood vessels. It comes from some life experience and observation: my dad had a heart attack a few years ago and passed away. I was so sad and cannot accept it at that time. He should have lived a much longer life, since his mother, my paternal grandma, lived up to ninety-six. My dad loved to eat fish and most of the listed healthy food above, but it was fried fish, and often the fish was cooked using lots of cooking oil. And growing up, I love to eat fish too and learned how to cook.

However, traditional Chinese cooking uses too much vegetable oil and makes the kitchen very greasy and hard to clean up. To avoid using cooking oil, I put one thick layer of onions at the bottom of the pot, and then put fish on top of it. That will prevent the fish from being burned, since the onion has lots of water in itself. I add some cooking wine after a few minutes, then a few spoons of soy sauce, simmer until it is fully cooked. I usually use two big onions for one dish. Therefore, I slightly changed the way of cooking by substituting cooking oil with onions. And that may make a huge difference in our health in the long run.

I also checked the effect of onion online and found some interesting papers $[4,5]$. It is a super-healthy food: excellent sources of vitamin C, low in calories and sodium, contains no fat nor cholesterol, and a natural antioxidant linked to preventing cancer. It may help reducing the risk of Parkinson's disease, cardiovascular disease and stroke [5]. However, eating raw onion in large amount may cause stomach irritating, so I would prefer to eat the cooked. I add more onions to all my dishes these days. For example, to cook a pot roast, I would cook the beef twice using a pressure cooker. First cook the beef in high pressure for about 50 minutes, with half cup of wine and a few pieces of ginger, cool it done to remove all fatty stuff on the top; then add one big chopped onions, other vegetables, soy sauce, and a cup of water to cook another 10 minutes. It is delicious and there is little fat in the dish to clog the blood vessels.

Some of my friends in my age try to avoid eating pizza, saying that it will cause cardiovascular disease due to the cheese and the meat. Anyway, we love pizza and eat it about twice a week. We also occasionally eat out in a restaurant when I want to take a break from cooking, though I know their food is not very healthy. But adding onions in most dishes at home seems to fend that off.

Finally, I know this is really a very small sample size observation (by checking two close family members); and as a statistician, I should have some data to support the conclusion that adding onions to your cooking will clean your blood vessels. However, no such research seems to be carried out so far, or maybe I am just ignorant of that. Anyway, I wish that you can try it in your own cooking after reading this, and enjoy a long, happy and healthy life. God bless your heart!

\section{References}

1. Yang XL, Liu GZ, Tong YH, Yan H, Xu Z, et al. (2015) The history, hotspots, and trends of electrocardiogram. J Geriatr Cardiol 12(4): 448-456.

2. Gillinov M, Nissen S (2012) Heart 411: the only guide to heart health you'll ever need. Three Rivers Press, New York, USA.

3. Skerrett PJ, Willett WC (2010) Essentials of healthy eating: a guide. J Midwifery Womens Health. 55(6): 492-501.

4. Griffiths G, Trueman L, Timothy Crowther T, Thomas B, Smith B (2002) Onions-a global benefit to health. Phytother Res 16(7): 603-615.

5. Suleria HA, Butt MS, Anjum FM, Saeed F, Khalid N (2015) Onion: nature protection against physiological threats. Crit Rev Food Sci Nutr 55(1): 50-66. 